\title{
The Effect of New Immunostimulants of Tissue and Plant Origin on the Morphological Characteristics of the Immune System's Central Organs and the Dynamics of Serum Immunoglobulins
}

\section{George Bazekin ${ }^{1 *}$, Evgeny Skovorodin ${ }^{1}$, Ilgiz Dolinin ${ }^{1}$, Ildar Gatiyatullin $^{1}$, Ivan Chudov ${ }^{1}$, Asiya EzhKova ${ }^{2}$}

${ }^{1}$ Department of Morphology, Pathology, Pharmacy and Non-Communicable Diseases, Federal State Budget Educational Institution of Higher Education "Bashkir State Agrarian University", 50-letia Octyabrya str., 34, Ufa, 450001, Russian Federation; ' Department of Physiology and Pathological Physiology, Federal State Budgetary Educational Establishment of Higher Education "Kazan State Academy of Veterinary Medicine named after N.E. Bauman", SibirskiyTract str. 35, Kazan, 420029, Russian Federation.

\begin{abstract}
This paper aims to study the influence of new immunostimulants of tissue and plant origin on the morphological characteristics of the immune system the dynamics of serum immunoglobulins. The conducted research revealed the beneficial effect of glycyrrhizic acid (GA) on the body of sick animals, promoting their growth and development, improving animals' clinical and physiological parameters. GA showed a positive effect on the cellular and humoral factors of natural resistance of calves with bronchopneumonia. Thus, GA activates biochemical processes and immune response aimed at the coordinated use of energy resources. It results in a favourable outcome of the disease due to activated metabolism and positively affects calf growth and development. Biostimulator Nucleostim is a purified extract of bovine spleen containing at least $1 \mathrm{mg} / \mathrm{ml}$ of low molecular weight peptides. At the end of the experiment, the survival rate of the experimental group of fowl treated with nucleostim increased to $88 \%$ compared to $72 \%$ of the control group. Nucleostimbiostimulant as a feed additive for chickens restores the histological architecture of the thymus with differentiation of the well-distinguished cortex and the medulla. It increases the mitotic activity of thymocytes, improves blood supply to the organ.
\end{abstract}

Keywords | Calves, Glycyrrhizic acid, Immunoglobulins, Morphology, Nucleostim

Received | May 26, 2021; Accepted | August 02, 2021; Published | September 25, 2021

*Correspondence | George Bazekin, Department of Morphology, Pathology, Pharmacy and Non-Communicable Diseases, Federal State Budget Educational Institution of Higher Education “Bashkir State Agrarian University”, 50-letia Octyabrya str., 34, Ufa, 450001, Russian Federation; Email: gebazekin4@ rambler.ru Citation | Bazekin G, Skovorodin E, Dolinin I, Gatiyatullin I, Chudov I, Ezhkova A (2021). The Effect of new immunostimulants of tissue and plant origin on the morphological characteristics of the immune system's central organs and the dynamics of serum immunoglobulins. Adv. Anim. Vet. Sci. 9(11): 1800-1809. DOI | http://dx.doi.org/10.17582/journal.aavs/2021/9.11.1800.1809

ISSN (Online) | 2307-8316; ISSN (Print) | 2309-3331

Copyright (C) 2021 Bazekin et al. This is an open access article distributed under the Creative Commons Attribution License, which permits unrestricted use, distribution, and reproduction in any medium, provided the original work is properly cited.

\section{INTRODUCTION}

L arge industrial farms detect about $75 \%$ of noninfectious diseases, including conditions of the digestive and respiratory systems, metabolic disorders, oario-and hysteropathy. Young farm animals are also susceptible to non-infectious and infectious diseases (colibacteriosis, salmonellosis, pasteurellosis and anaerobic enterotoxemia), followed by pneumonia (Bliard et al., 1994; Gabitovet al., 2019; Skovorodin et al., 2018).
There is a large volume of published studies describing the use of new biostimulants of tissue and plant origin in the animal breeding and poultry industry (Wang et al., 2018; Skovorodin et al., 2018; Okovity et al.,2020; Pushkarevetal., 2021; Makarova et al., 2021).

More recent attention has focused on effective supplements and their application to correct the natural resistance, immune-biological protective and adaptive properties in animals and fowls. The academic literature on biological 
stimulants (tissue preparations) has revealed their beneficial effects on the body of animals and poultry. Their application provides an increase in body weight, better biochemical and haematological blood parameters (Dementyev et al., 2018; Khasanov et al., 2019; Sultanova et al., 2019).

Biostimulants in cows' diet improve milk qualitative composition and technological characteristics and affect its fat and protein content. There is evidence that animals given a biostimulant have the best cheese-making properties. Their milk coagulated faster under the action of rennet, forming a dense and elastic clot (Sultanova et al., 2019).

Glycyrrhizic acid, a triterpene glycoside, is a promising substance. It is based on a biologically active component, a liquorice root extract.

Glycyrrhizic acid, extracted from Licorice root, is a monodesmosidic triterpenoid saponin. It is widely used in cosmetic and pharmaceutical applications due to its antiinflammatory properties, and is an ingredient in foods as a sweetener additive. It has an additional attraction due to its gel forming properties at relatively low concentrations. Although it has attracted much recent attention, many of its basic surface active characteristics, adsorption and selfassembly, remain relatively unexplored. How the structure of the Glycyrrhizic acid saponin affects its surface active properties and the impact of gelation on these properties are important considerations, and to investigate these are the focus of the study (Tucker et al., 2021).

Previous research has established antiarrhythmic, antiallergic, antiviral and anti-inflammatory effects of GA (Baltina et al., 2001, 2006, 2009a, 2009b, 2010; Jitesh and Geetha, 2017).

A GA molecule of a pleiotropic effect, including anti-inflammatory, antioxidant, antifibrotic and immunomodulating properties, is a rational therapeutic choice. GA's therapeutic properties against infectious and non-infectious liver diseases have been proved by multiple clinical investigations, including randomized placebocontrolled studies conducted both in Russia and abroad. It has been suggested the use of a combination of glycyrrhizic and ursodeoxycholic acids based on the potential antiinflammatory and anticholestatic synergism of the two molecules (Okovity et al., 2020).

GA exhibits a potent immune regulatory effect to activate chicken macrophages and enhances Salmonella-killing capacity (Wang et al., 2018).

GA receives growing interest due to its high and diverse biological activity at low toxicity than synthetic analogues.
It evokes the humoral immune response in animals primed with thymus-dependent antigen. GA has antiinflammatory, ulcerogenic, blood hepatoprotective and antioxidant properties (Bazekin et al., 2012, 2015, 2021; Beskina et al., 2006; Tolstikova et al., 2009).

Several authors have proved the efficacy of different glycyrrhizic acid derivatives in antibacterial therapy for experimental infections. Many studies have shown higher nonspecific resistance to infection when stimulating the mononuclear phagocytic system (Skovorodin et al., 2018).

To date, veterinary medicine offers a wide range of medicines to stimulate the nonspecific immune status. Many drugs used in veterinary medicine have undesirable effects: Allergenicity, high cost, high toxicity, pyrogenicity, etc. (Buttros et al., 2009; Ming and Yin, 2013; Nishi et al., 2019).

The issues of rational, economically feasible fattening of poultry meat, namely broiler chickens, are an urgent task. It is also important to find effective application methods to adjust the fowl natural resistance, immune and biological reactivity.

The agricultural food industry is currently facing significant challenges. The development of the food industry, biotechnology, chemistry and related sciences has brought a huge number of new substances that can have a negative effect on humans, the level of environmental pollution has increased, which necessitates stricter requirements for food safety. The relevance of the problems of producing organic food, which has recently gone far beyond the boundaries of purely scientific interests, has made them the subject of discussion for various sectors of society. The demand for safe, environmentally friendly and biologically clean, and high-quality food is growing. At the same time, the production of agricultural and food products should be cost-effective. Today, bio-food markets have already formed in the world: these are plant growing products (fruits, vegetables), animal husbandry (dairy products), baby food, and grain. The growth of the cultural level of the population will increase the demand for beef and its processed products. In this regard, the study and search for safe natural components that affect the yield of meat and are able to efficiently convert the energy of food into organic protein are critical. The paper presents the results of studies of beef meat grown using the technology of intensive cultivation using a biostimulator of natural origin. A positive effect of humic natural substances on carcass morphology and beef quality has been proven. An additional reserve to provide an increase in consumer value and production of safe meat raw materials using a natural peat preparation is shown (Guberet al., 2020). 
Nucleostimbiostimulant is a purified extract of bovine spleen containing at least $1 \mathrm{mg} / \mathrm{ml}$ of low molecular weight peptides (nucleotides and nucleosides) formed due to autolysis, using dry serum and diatomite as fillers.

Existing research recognizes a stimulating effect of biostimulants on the fowl liver, improved chicken viability and higher body weight gain. The biological stimulant Nucleostim as an adaptogenic, anabolic and immunestimulating agent is promising to search for new medicines that improve poultry health and productivity (Dolinin et al., 2020).

A biostimulant based on the animal spleen increases the natural resistance of young farm animals and reduce their morbidity. Biostimulant is used to prevent gastrointestinal diseases in animals and increase the natural resistance of the body. It reduces the disease rate of young animals, enhances their growth and development and ensures maximum safety. Biostimulants are considered suitable and effective in increasing immune protection, preventing gastrointestinal diseases, maintaining animals safety and productivity (Makarova et al., 2021).

Pushkareva et al. (2021) studied the effect of a tissue biostimulant. The research results demonstrated the best immune status of the second experimental group heifers, having the highest indicators of spontaneous Nitro Blue Tetrazolium Reduction Test (NBT-test) by $12.5 \%$ ( $\mathrm{p} \leq 0.01$ ), stimulated NBT-test by $10.0 \%$ ( $\mathrm{p} \leq 0.05)$, phagocytic index by $5.8 \%(\mathrm{p} \leq 0.05)$ compared to the control animals (Pushkarev et al., 2021).

Currently, herbal-based treatment is becoming more and more popular since phytopreparations are more efficient and safe than chemical medicines. It is the composition of herbal remedies that makes them advantageous over synthetic drugs. It is believed that biostimulants are a valuable biogenetic complex containing vitamins, microelements and other substances. To date, there are a large number of medicines. Most of them are of high cost, require a lengthy application and are difficult to administer.

The search for new treatment methods based on existing medicines and the development of new, more effective drugs that do not cause resistance and have a pronounced immunostimulating effect is very relevant in medicine and veterinary medicine (Bazekin et al., 2012, 2021).

The research aim is to study the effect of new immunostimulants of tissue and plant origin on the morphological characteristics of the immune system and the dynamics of serum immunoglobulins.
Tasks: (1) To study the effect of the biological stimulant Nucleostim on histological and immune histochemical changes in the bursa and thymus. (2) To examine the impact of glycyrrhizic acid on the immunological parameters and biochemical status of animals with acute bronchopneumonia.

\section{MATERIALS AND METHODS}

\section{ETHICAL APPROVAL}

All experiments were performed in conformity with the Law (The European Convention for the protection of vertebrate animals, European convention for the protection of vertebrate animals used for experimental and other scientific purposes; Guide for the care and use of laboratory animals and the Animal Ethics Committee report (No. 6 dated 02.03.2017).

\section{ANimal FEeding, MANAGEMENT, EXPERIMENTAL}

\section{DESIGN AND TREATMENTS}

The work was performed at the Department of Morphology, Pathology, Pharmacy and Non-Infectious Diseases of the Bashkir State Agrarian University in the period from 2019-2020. The first experiment was conducted on 50 crossRoss 308 broiler chickens. The second series of experiments was carried out in the conditions of the state farm "Alekseevsky" of the Bashkortostan Republic. The research target was 24 black-and-white calves with an acute form of bronchopneumonia. The research was carried out in the vivarium of the veterinary clinic and the biochemical laboratory of the Faculty of Biotechnology and Veterinary Medicine of the Bashkir State Agrarian University, the Republic of Bashkortostan.

The experimental part of the research was divided into series. The first experiment was conducted on 50 crossRoss 308 broiler chickens. Control and experimental groups of fowl were kept in equal conditions. Access to water was unlimited. A feed was balanced. A new biostimulant Nucleostim was used as an additive. The biostimulant was given with the feed, following the instructions. The thymus and bursa (central organs of the immune system) were the research material. The fowl organs were weighed with scales. The thymus and bursa were fixed with $10 \%$ formalin and dehydrated in alcohol. Then they were immersed in paraffin. Histological sections were made on a Leica RM 2145 microtome and stained with hematoxylin and eosin according to the generally accepted Van Gieson method.

The second set of experiments was carried out on 24 black-and-white calves. The main liquorice triterpene glycoside, glycyrrhizic acid, was used. The studied calves were administered $50 \mathrm{mg} / \mathrm{kg}$ of glycyrrhizic acid in the form of aqueous solutions using rubber bottles once a day. 
It is advisable to study the natural resistance of calves with bronchopneumonia, taking into account the properties of the glycyrrhizic acid components. At the initial stage, the calves were examined. The examination showed that 24 calves had acute bronchopneumonia. 4 groups of calves were formed to conduct an experiment. The sick animals were divided into three experimental groups and one control group of 6 calves each. The animals were kept in the same conditions during the experiment.

Venous blood samples were collected in vacuum tubes after an overnight fast for biochemical analyses of blood serum with a clot activator.

Blood samples taken for biochemical studies were centrifuged in an EVA 20 centrifuge at $3500 \mathrm{rpm}$ for 10 minutes.Biochemical blood tests were performed using a biochemical blood analyzer using standardized reagents from Vital Diagnostics Spb.

Statistical processing of experimental data was carried out using the statistical analysis package for Microsoft Excel. The statistical significance between the groups in terms of quantitative characteristics was assessed using the Student's t-test. The differences were considered statistically significant at $\mathrm{P}<0.05$.

The authors declare that the work is written with due consideration of ethical standards. The study was conducted in accordance with the ethical principles approved by the Ethics Committee of Federal State Budgetary Educational Establishment of Higher Education "Bashkir State Agrarian University” (Protocol No. 6 of 13.06.2020).

\section{RESULTS OF HISTOLOGICAL}

AND

\section{IMMUNOHISTOCHEMICAL STUDIES IN BROILER} CHICKENS OF THE POCC 308 CROSS AFTER APPLICATION OF "NuCLEOSTIM"

The Nucleostim application resulted in the following changes. The control group fowls have a typical lobular structure of the organ. The thymus is externally covered with a connective tissue membrane that penetrates the thickness of the parenchymal organ and divides it into incomplete lobules. Each lobule contains a dark-colored cortical substance located on the lobule periphery and contains mainly small T-lymphocytes, epithelioretic cells and macrophages (Figure 1).

The medulla is lighter, centrally localized, and contains epithelioretic cells, mature T-lymphocytes, Gassal corpuscles, and single lipid droplets. The boundaries between cortical and cerebral matter were differentiated and clear. Arterioles and venules were full-blooded, with a free lumen. No perivascular infiltration was detected
(Figure 2).

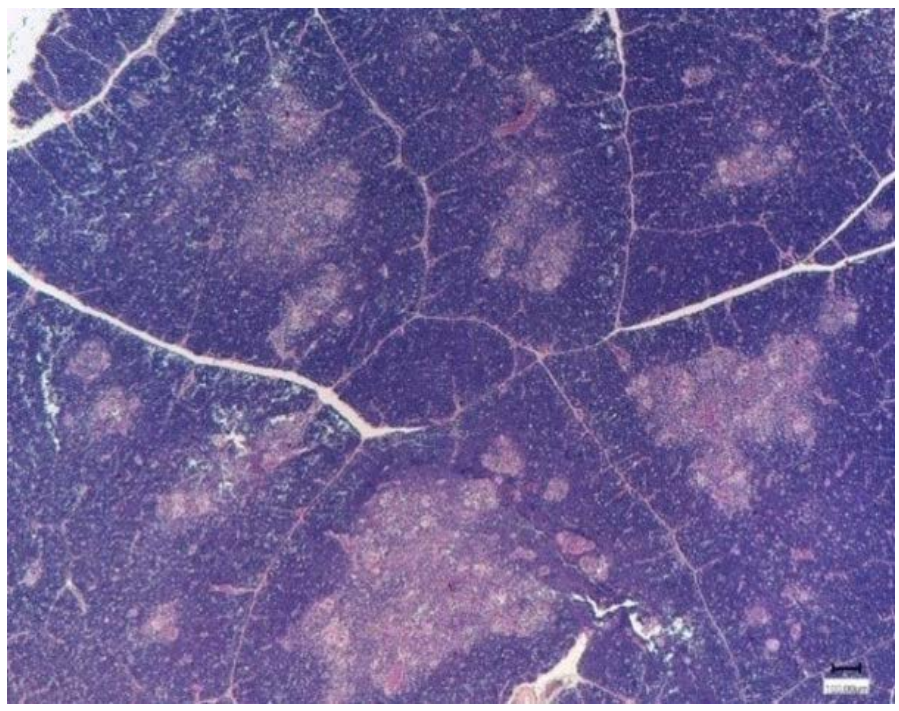

Figure 1: Thymus of broiler chickens in the control group. Stained with hematoxylin and eosin.

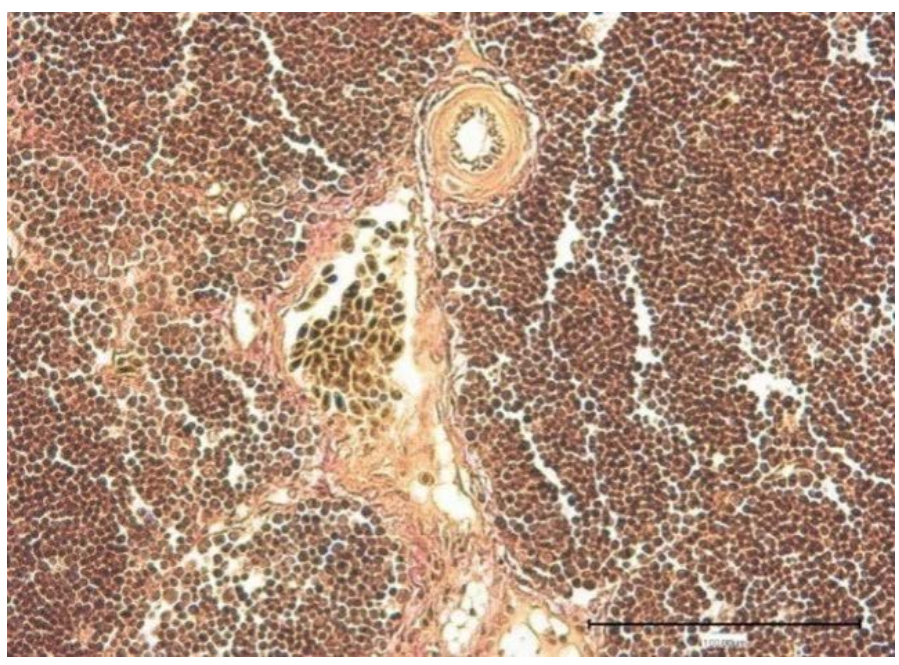

Figure 2: Thymus of broiler chickens in the control group. Blood vessels. Stained by Van Gieson.

The thymus histology of experimental broiler chickens had no distinctive features compared to the control after the Nucleostim application. The thymus structure was lobular; each of the lobules had a cortex and a medulla. They were well depicted and differed in their structure. In the septa perenchyma loose fibrous connective tissue formed trabeculae, which is represented by thin layers (Figure 3).

In the experimental group, the hematothymus barrier was strengthened, visualized near the vessels. The fibrous connective tissue was found growing (Figure 4). In addition, the medulla in the experimental group was found to have the following cells like macrophages, Gassal bodies (differentiated and young), reticuloendothelial cells and T-lymphocytes. The thymus lobules differed from the experimental groups; they were enlarged in the experimental group. 


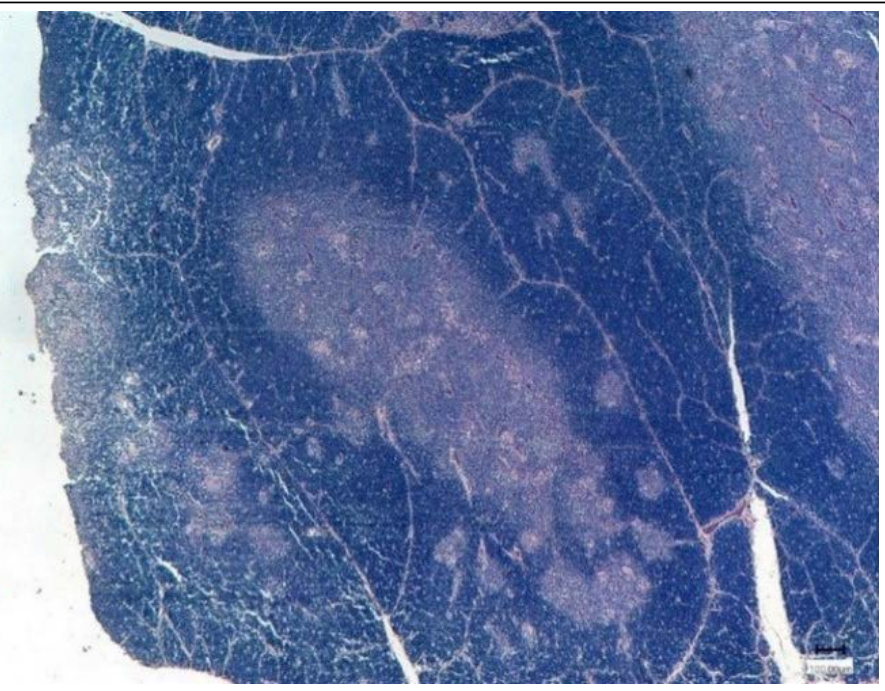

Figure 3: Thymus of the experimantal chickens (Nucleostim, $10 \mathrm{~g} / \mathrm{kg}$ of feed). Stained with hematoxylin and eosin.

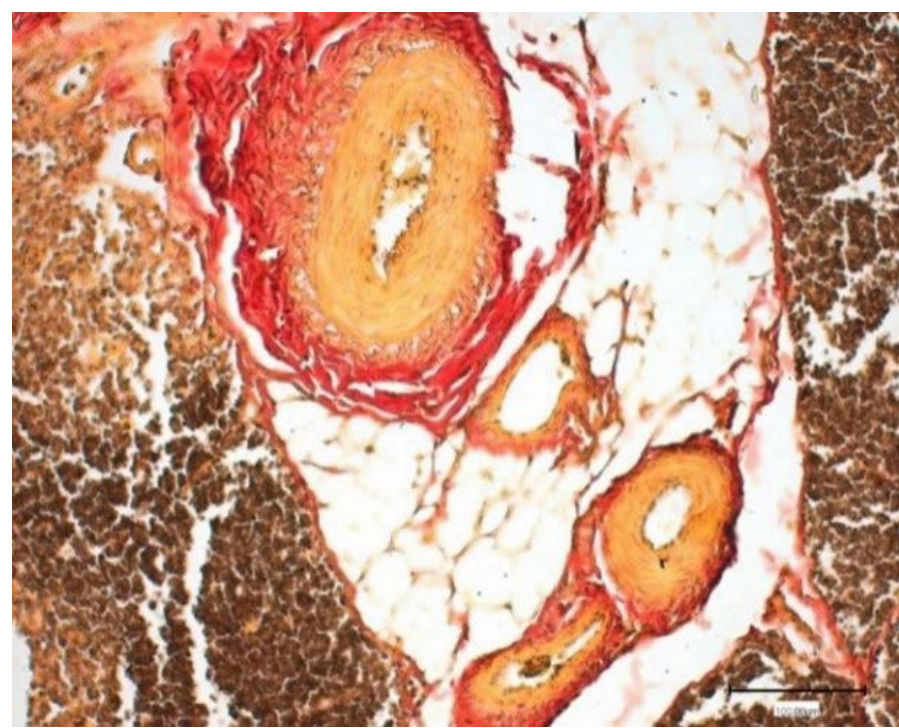

Figure 4: Thymus of the control chickens (Nucleostim, 10 $\mathrm{g} / \mathrm{kg}$ of feed). The growth of loose fibrous connective tissue. Stained by Van Gieson.

Thus, the control broiler chickens had 1.2 times lower thymus cortex thickness and 1.8 times less the medulla than the experimental group after the Nucleostim application (Figure 5).

Hence, after the Nucleostim administration at a dose of $10 \mathrm{~g} / \mathrm{kg}$ of feed, the experimental broiler chickens had hypertrophy of the thymus lobules (Figure 6).

The experiments showed that Nucleostim given to the broiler chickens at a dose of $10 \mathrm{~g} / \mathrm{kg}$ of feed proved to have an immune-modulating effect, expressed in normal hypertrophy and hyperplasia of the thymus.

The Bursa of Fabricius (Bursa) of the control broiler chickens had 15-20 longitudinal folds with polygonal follicles forming a slit-like structure of the organ with a narrowed lumen of the cloacal outgrowth. Follicles at folds had two layers separated by strands of loose fibrous connective tissue with blood vessels (arterioles and venules). The lumen of the lymphatic vessels was enlarged. The interstitial spaces are sharply expanded, due to edema. Besides, there were signs of reduction and desolation of some lymphoid nodules. The surface of each fold was covered with interfollicular epithelium and follicular epithelium.

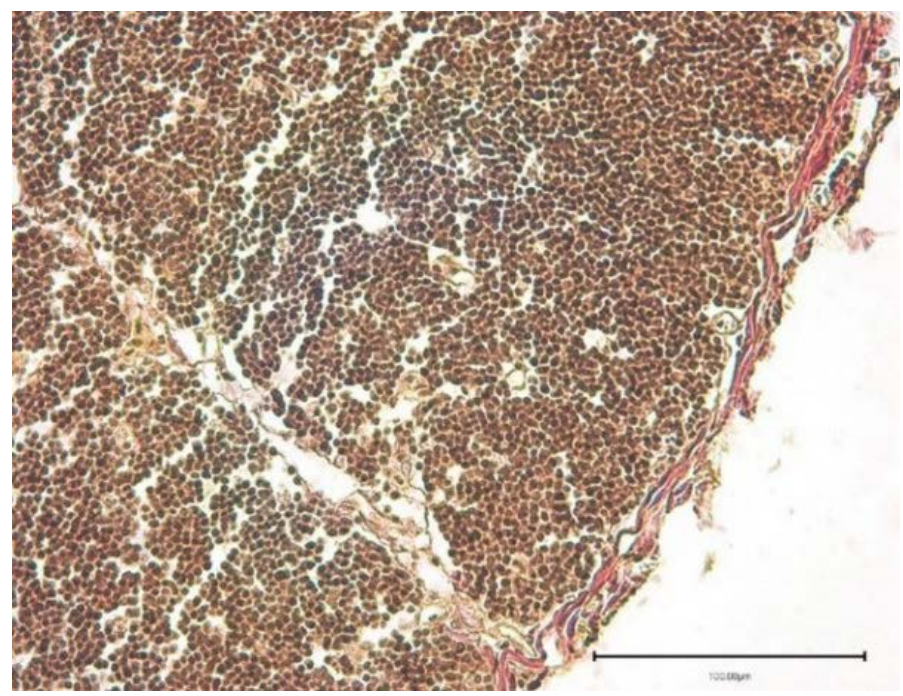

Figure 5: Thymus of the control broiler chickens. Connective tissue capsule. Stained by Van Gieson.

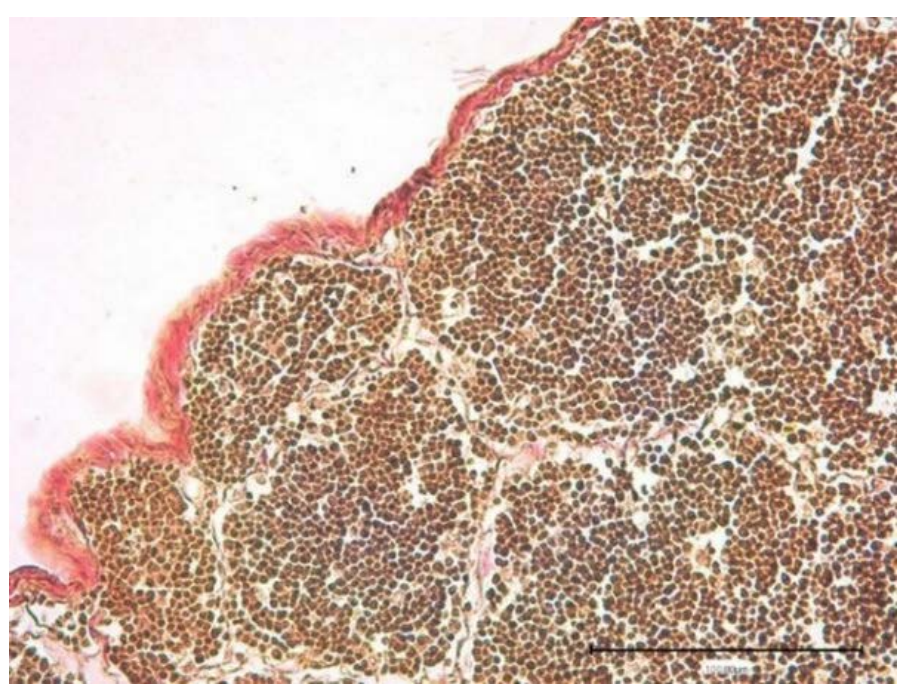

Figure 6: Thymus of the control chickens (Nucleostim, 10 $\mathrm{g} / \mathrm{kg}$ of feed). Connective tissue capsule. Stained by Van Gieson.

The lymphoid follicles or lobules were clearly visible and had cortical and medullary parts in the bursa (Fabricius sac) of broiler chickens in the control group. Lymphocytes, macrophages, and plasmocytes had an appearance of a thin band, located along the edge of the lobule (lymphoid follicle) of the bursa (Fabricius sac) cortex. The bursa medulla consisted of lymphocytes, lymphoblasts, 
dendritic cells, granulocytes, and reticular cells. Medulla delymphotizationwas characterized by a thinning of the cell concentration. In the control group, the bursal cortex was separated from the medulla by a membrane and a network of capillaries (Figure 7).

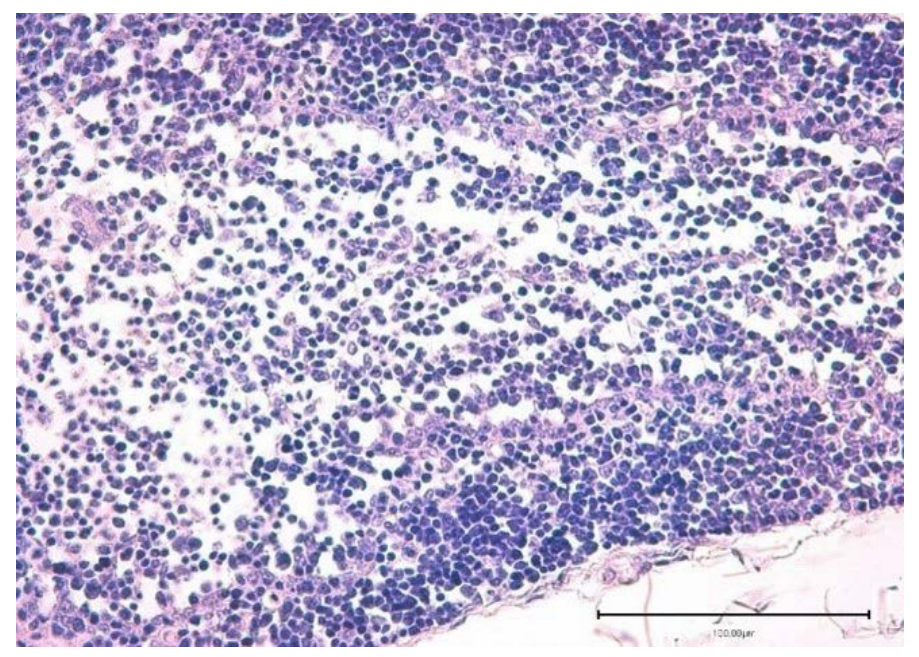

Figure 7: The bursa lobule (lymphoid follicle) of the control broiler chickens. Stained with hematoxylin and eosin.

The epithelial cells of the organ formed a network that transferred into the epithelial linings of the organ lumen. The bursal folds were covered with pseudostratified epithelium.

The cortex substance of the lymphoid follicles had a dense population of pseudoeosinophils that could indicate on immune-inflammatory processes.

Blood channels had no prominent changes. The venules were moderately dilated, full-blooded, and the endotheliocytes are flattened. The lumen of the arterioles is free, expanded.

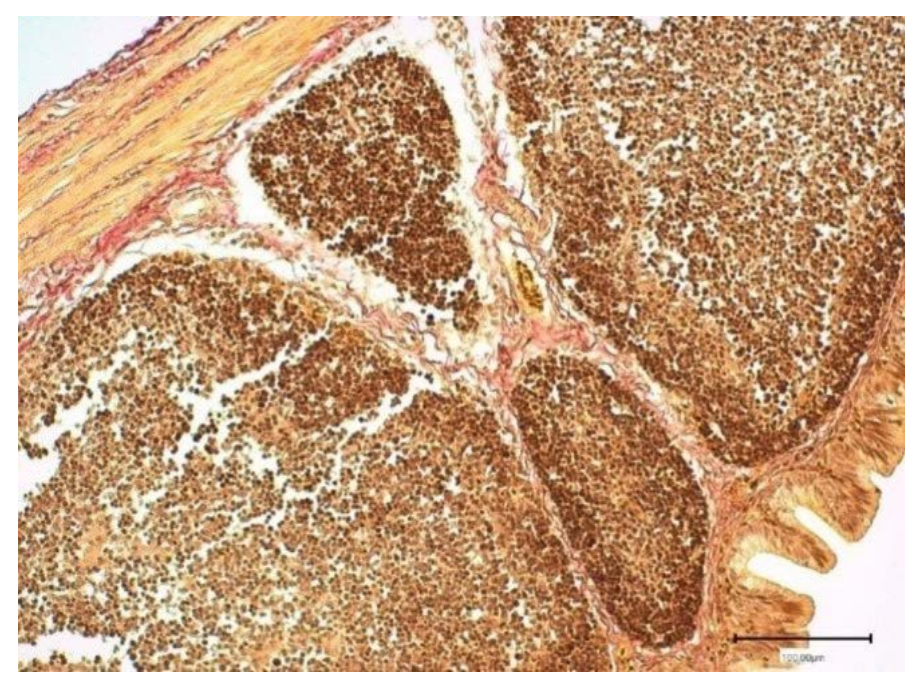

Figure 8: The bursa fold stroma of cross-breed ROSS308 broiler chickens in the experimental group (Nucleostim, $10 \mathrm{~g} / \mathrm{kg}$ of feed). Stained by Van Gieson.
The broiler chickens, given the biostimulant Nucleostim 10 $\mathrm{g} / \mathrm{kg}$, had the following bursa morphology. The lymphoid nodules were extensive, adjacent to each other, and had a polygonal shape. The medullary and cortical layers were dense. The lymphoid nodules arranged in several rows; the shape is different. Blood vessels are unchanged (Figure 8). The epithelium lining the folds arranged in a single cylindrical row, forming villi.

The broiler chickens administered $10 \mathrm{~g} / \mathrm{g}$ of the Nucleostim biostimulant had the lymphoid nodules tightly adjacent to each other, arranged mostly in two rows; the cortical part was more prominent with a higher cell density. The lymphoid nodule had multiple germinal centres with high infiltrative and proliferative activity. The number of germinal centres in the lymphoid follicles of the experimental group was higher by 2.36 times compared to the control group.

Thus, the Fabricius bursa of broiler chickens given $10 \mathrm{~g} / \mathrm{kg}$ of the Nucleostimbiostimulant has a high level of functional dynamics. Morphologically significant signs of this activity are mucosal hyperplasia and multiple lymphoid nodules with numerous germinal centres, the thickened cortex of the lymphoid follicle. They indicate the intensive growth of new nodules in the control group being a mark of apoptosis inhibition. In the experimental group of broiler chickens, there was a delay in bursa involution.

In contrast to the experimental fowls, the bursa of the control poultry demonstrates progressive involutional processes, manifested in the thinner cortex, lower medulla density, increased relative area of the fold stroma, desolation and deformation of nodules, rearrangement of the singlerow cubic epithelium of the lateral surfaces of the folds into pseudo-multi-layered.

\section{RESULTS OF BIOCHEMICAL AND IMMUNOBIOLOGICAL} STUDIES IN CALVES AFTER THE USE OF GLYCYRRHIZIC ACID

The second series of experiments revealed intensified bronchopneumonia in animals. Sick animals had reduced appetite, pale, cyanotic mucous lining, longer lying times, high temperature, refusal to feed and drink, rapid pulse and breathing. In the first days of the disease, they had rapid breathing, coughing, rattling sounds and leakage from the nasal cavity. Sick calves had purulent nasal discharge on 3-5 days. During the standard treatment for bronchopneumonia, the calves of the experimental group (12 heads) received GA at a dose of $50 \mathrm{mg} / \mathrm{kg}$. The calves of the second group were the control (12 heads), they were treated according to the standard scheme.

Table 1 shows the results of biochemical parameters of the calf serum. 
Table 1: Serum biochemical parameters of sick calves, when using glycyrrhizic acid $(n=12)$.

\begin{tabular}{|c|c|c|c|c|c|}
\hline \multirow[t]{2}{*}{ Parameters } & \multirow{2}{*}{$\begin{array}{l}\text { Units of meas- } \\
\text { ure }\end{array}$} & \multirow[t]{2}{*}{ Control group } & \multicolumn{3}{|c|}{ Experimental groups } \\
\hline & & & before using GA & $\begin{array}{l}\text { after } 5 \text { days of applying } \\
\text { GA }\end{array}$ & $\begin{array}{l}\text { after } 10 \text { days of applying } \\
\text { GA }\end{array}$ \\
\hline Total protein & $\mathrm{g} \%$ & $7.66 \pm 0.55$ & $6.9 \pm 0.78$ & $8.01 \pm 0.54$ & $8.09 \pm 0.65$ \\
\hline Albumins & $\%$ & $30.6 \pm 2.03$ & $30.5 \pm 1.29$ & $41.3 \pm 2.03$ & $43.4 \pm 2.45$ \\
\hline$\alpha$-globulins & $\%$ & $22.3 \pm 1.27$ & $23.9 \pm 1.32$ & $20.4 \pm 1.32$ & $17.34 \pm 1.34$ \\
\hline$\beta$-globulins & $\%$ & $22.4 \pm 1.22$ & $23.7 \pm 1.43$ & $17.3 \pm 1.24$ & $17.9 \pm 1.32$ \\
\hline$\gamma$-globulins & $\%$ & $24.8 \pm 1.34$ & $24.9 \pm 1.34$ & $19.8 \pm 1.32$ & $18.2 \pm 1.43$ \\
\hline Total bilirubin & $\%$ & $5.31 \pm 0.36$ & $5.09+0.24$ & $4.79 \pm 0.37$ & $4.61 \pm 0.36$ \\
\hline Alkali reserve & vol. $\% \mathrm{CO}_{2}$ & $37.6 \pm 3.00$ & $35.4 \pm 2.07$ & $39.2 \pm 2.12$ & $46.7 \pm 2.67$ \\
\hline ESR & $\min$. & $12.1 \pm 1.11$ & $13.5 \pm 1.15$ & $8.23 \pm 0.11$ & $7.63 \pm 0.56$ \\
\hline
\end{tabular}

Note: $\mathrm{P} \leq 0.05$

The use of GA at the beginning of the experiment showed the reduced total protein, albumin, and alkaline reserve in the blood serum of sick animals. The content of $\alpha$-globulins, $\beta$-globulins, $\gamma$-globulins, total bilirubin, and erythrocyte sedimentation rate were increased. On the fifth day after the GA application, calves with bronchopneumonia had decreased total protein, alkaline reserve, and albumin by 0.9 times.

After 10 days the GA use, the amount of total protein increased by 1.04 times; albumin by 1.3 times; alkaline reserve by 1.04 times. The number of globulins decreased: $\alpha$-globulins by 0.9 times; $\beta$-globulins by 0.7 times, $\gamma$-globulins reduced by 0.8 times; the rate of erythrocyte sedimentation holds down by 1.4 times.

The conducted research revealed the beneficial effect of glycyrrhizic acid (GA) on the body of sick animals, promoting their growth and development, improving animals' clinical and physiological parameters. The daily live weight gain of calves in the experimental group at the age of one a half month exceeded the analogues from the control group by $278.45 \mathrm{~g}$ or $67.51 \%$; at the age of three months by $178.1 \mathrm{~g}$ or $38.5 \%$; at the age of four months by $234.32 \mathrm{~g}$ or $48.35 \%$.

Table 1 shows that before the use of glycyrrhizic acid at the beginning of the experiment, the content of total protein $(6.9 \pm 0.78 \mathrm{~g} \%)$, albumin $(30.5 \pm 1.29 \%)$, and alkaline reserve $(35.4 \pm 2.07 \mathrm{vol} \% \mathrm{CO} 2)$ in the blood serum of sick calves was reduced. The level of $\alpha$-globulins $(23.9 \pm 1.32)$, $\beta$-globulins (23.7 $\pm 1.43 \%), \gamma$-globulins $(24.9 \pm 1.34 \%)$, total bilirubin $(5.09 \pm 0.24 \%)$, the erythrocyte sedimentation rate $(13.5 \pm 1.15 \mathrm{~min})$ was increased.

On the fifth day after the GA application the amount of total protein $(8.01 \pm 0.54 \%)$, alkaline reserve $(39.2 \pm 2.12$ vol\%CO2) and albumin $(41.3 \pm 2.03 \%)$ in the blood of calves with bronchopneumonia increased 0.9 times.
10 days after administering GA, there was an increase in total protein $(8.09 \pm 0.65 \%)$, i.e. by 1.04 times; albumin $(43.4 \pm 2.45 \%)$, i.e. by 1.3 times; alkaline reserve $(46.7 \pm 2.67$ vol\% CO2), i.e. by 1.04 times. The amount of globulins decreased: $\alpha$-globulins $(17.34 \pm 1.34 \%)$, i.e. by 0.9 times; $\beta$-globulins $(17.9 \pm 1.32 \%)$, i.e. by 0.7 times, $\gamma$-globulins $(18.2 \pm 1.43 \%)$, by 0.8 times; the rate of erythrocyte sedimentation $(7.63 \pm 0.56 \mathrm{~min})$ decreased by 1.4 times.

The conducted research revealed the beneficial effect of glycyrrhizic acid on the body of sick animals, promoting their growth and development, improving animals' clinical and physiological parameters. The daily live weight gain of calves in the experimental group at the age of one a half months exceeded the analogues from the control group by $278.45 \mathrm{~g}$ or $67.51 \%$; at the age of three months by $178.1 \mathrm{~g}$ or $38.5 \%$; at the age of four months by $234.32 \mathrm{~g}$ or $48.35 \%$.

The experimental calves given GA at a dose of $50 \mathrm{mg} / \mathrm{kg}$ exceeded the control calves by daily weight gain.

The conducted scientific research established the positive effect of glycyrrhizic acid on cellular and humoral factors of natural resistance of calves with bronchopneumonia.

Analyses of the biochemical studies showed that before the GA use at the beginning of the experiment, the content of total protein, albumin, and alkaline reserve in the blood serum of sick calves were reduced. The content of $\alpha$-globulins, $\beta$-globulins, $\gamma$-globulins, total bilirubin, and erythrocyte sedimentation rate were increased.

On the fifth day after the GA application, calves with bronchopneumonia had decreased total protein, alkaline reserve, and albumin by 0.9 times. In addition, the percentage of globulins significantly decreases, $\alpha$-globulins, $\beta$-globulins by 0.9 times; $\gamma$-globulins by 0.1 times, and the rate of erythrocyte sedimentation decreased by 0.8 times. The total bilirubin content is reduced by 0.9 times. 
After 10 days the GA use, the amount of total protein increased by 1.04 times; albumin by 1.3 times; alkaline reserve by 1.04 times. The number of globulins decreased: $\alpha$-globulins by 0.9 times; $\beta$-globulins by 0.7 times, $\gamma$-globulins reduced by 0.8 times; the rate of erythrocyte sedimentation holds down by 1.4 times.

The use of glycyrrhizic acid had a positive effect on the cellular and humoral parameters of nonspecific resistance in patients with bronchopneumonia of calves, which contributed to a reduction in the duration of treatment (Bertagnon et al., 2019).

The effect of the biopreparation on the internal organs was assessed by the state of immunity (thymus, bursa). Special attention was paid to the central organs of the immune system in fowls, since they all grow intensively in the first months of life and reach maximum development: the thymus by $3.5-4$ months, and the bursa by $4-4.5$ months. The thymus then gradually atrophies upon reaching puberty (Nasrin et al., 2012; Skovorodin et al., 2018).

Studies have shown that throughout the experiment, the thymus was developing in chickens of all the groups, apparently due to improved feeding during the research.

The Nucleostimbiostimulant had a stimulating effect on the liver of experimental and control chickens. At the same time, the relative weight of the organ is less than in the control, indicating a physiological increase in the liver.

Blood morphological and immunological parameters of broiler chickens were studied by many researchers. However, there is no consensus on the dynamics of blood parameters of young chickens. The conducted studies found that they change depending on fowl age and physiological state, being evidence of the different intensity of metabolic processes. Many scientists have mentioned the stimulating effect of different biostimulants on hematopoiesis, and especially leucopoiesis.

The conducted morphological studies indicate that the use of Nucleostim did not significantly affect the dynamics of red and white blood parameters of poultry. During the experiment, they were within the physiological norm for a given age and productivity aims.

The minimum content of red blood cells and haemoglobin was recorded at the age of 30 days, which is consistent with the data of Russian and foreign researchers. After the application of Nucleostim, the content of red blood cells in the second experimental group (Nucleostim $10 \mathrm{~g} / \mathrm{kg}$ of feed) increased by $16 \%$ compared to the control.
The new biological stimulant Nucleostimis recommended for use in veterinary medicine as an adaptogenic, anabolic and immune-stimulating agent and is promising for the search for new drugs that improve the health and productivity of poultry.

\section{CONCLUSIONS AND RECOMMENDATIONS}

Nucleostimbiostimulant as a feed additive for chickens restores the histological architecture of the thymus with differentiation of the well-distinguished cortex and the medulla. It increases the mitotic activity of thymocytes, improves blood supply to the organ.

The Fabricius bursa of broiler chickens given $10 \mathrm{~g} / \mathrm{kg}$ of the Nucleostimbiostimulant has a high level of functional dynamics. Histological signs of such activity are mucosal hyperplasia and multiple lymphoid nodules with numerous germinal centres, the thickened cortex of the lymphoid follicle. They indicate the intensive growth of new nodules in the control group being a mark of apoptosis inhibition. The experimental broiler chickens were characterized by a delayed bursa involution.

The application of glycyrrhizic acid had a positive effect on the cellular and humoral parameters of nonspecificresistance of calves with bronchopneumonia, which shortened the treatment time. Thus, GA activates biochemical processes and immune response aimed at the coordinated use of energy resources. It results in a favourable outcome of the disease due to activated metabolism and positively affects calf growth and development.

\section{AUTHOR'S CONTRIBUTION}

All authors contributed equally.

\section{CONFLICT OF INTERESTS}

The authors have declared no conflict of interest.

\section{Funding}

This research did not receive any specific grant from funding agencies in the public, commercial, or not-forprofit sectors.

\section{REFERENCES}

- Baltina LA, Kondratenko RM, Baltina Jr LA, Plyasunova OA, Pokrovskii AG, Tolstikov GA (2009a). Search for new drugs: Prospects for the creation of new antiviral drugs based on glycyrrhizicacid and its derivatives. Pharm. Chem. J., 10: 539-548. https://doi.org/10.1007/s11094-010-0348-2

- Baltina LA, Kondratenko RM, Baschenko NZ, Stolyarova OV, Plyasunova OA (2009b). Synthesis and biological activity 
of new glycyrrhizic acid conjugates with amino acids and dipeptides. Russ. J. Bioorganic Chem., 35(4): 510-517. https://doi.org/10.1134/S1068162009040141

- Baltina LA, Kondratenko RM, Galin FZ, Plyasunova OA, Tolstikov GA (2006). Synthesis of glycyrrhizic acid conjugates containing 1-lysine. Chem. Nat. Compd., 42(5): 543-548. https://doi.org/10.1007/s10600-006-0210-7

- Baltina LA, Kondratenko RM, Mustafina SR, Flekhter OB, Murinov YI, Davydova VA, Zarudii FS, Ismagilova AF, Tolstikov GA (2001). Synthesis of glycyrrhizic acid from glycyrram and pharmaciological characterization of the product. Pharm. Chem. J., 1: 40-44. https://doi. org/10.1023/A:1010454810888

- Baltina LA, Kondratenko RM, Stolyarova OV, Plyasunova OA, Pokrovskii AG (2010). Synthesis and antiviral activity of $18 \alpha$-glycyrrhizic acid and its esters. Pharm. Chem. J., 44(6): 299-302. https://doi.org/10.1007/s11094-010-0454-1

- Bazekin GV, Ismagilova AF (2012). Effect of glycyrrhizic acid on veterinary, sanitary characteristics of milk during chronic intoxication with organophosphorus compounds. Russ. J. Prob. Vet. Sanitat. Hyg. Ecol., 1: 231-237.

- Bazekin GV, Ismagilova AF (2015). Effect of glycyrrhizic acid on the formation of meat quality of pigs after deworming against ascariasis. Proc. Orenb. State Agrar. Univ. 1(51): 115-117.

-Bazekin, G, Gatiyatullin I, Skovorodin E, Sharipov A, Dolinin I (2021). Morphofunctional assessment of the glycyrrhizinic acid effect on myocardium of rats under adrenaline loading. Pak. Vet. J., 3(40): 289-294. https://doi.org/10.29261/ pakvetj/2020.024

-Bertagnon HG, Batista CF, Santos KR, Gomes RC, Bellinazzi JB, Libera AM (2019). Alveolar macrophage functions during the transition phase to active immunity in calves. J. Anim. Sci., 9(96): 3738-3747. https://doi.org/10.1093/jas/ sky261

- Beskina OA, Abramov AY, Gabdulkhanova AG, Miller AV, Safronova VG, Zamaraeva MV (2006). Possible mechanisms of antioxidant activity of glyc https://doi.org/10.1134/ S1990750807010040 yrrhizic acid. Biomeditsinskaya Khimiya, 1: 60-68.

-Bliard C, Massiot G, Nazabadioko S (1994). Glycosylation of acids under phase transfer conditions. Partial Synthesis of saponins. Tetrahed. Lett., 35(33): 6107-6108. https://doi. org/10.1016/0040-4039(94)88088-3

-Buttros JB, Bergamaschi CT, Ribeiro DA, Fracalossi AC, Campos RR (2009). Cardioprotective actions of ascorbic acid during isoproterenol-induced acute myocardial infarction in rats. Pharmacology, 84(1): 29-37. https://doi. org/10.1159/000222245

- Dementyev EP, Bazekin GV, Tokarev IN, Lobodina GV, Karimov FA, Andreeva AV, Gizatullin RS, Ilyasova ZZ, Giniyatullin MG, Bliznetsov AV (2018). The application of physical and biological stimulants in livestock breeding. J. Eng. Appl. Sci., 13(10): 8325-8330.

-Dolinin I, Bazekin G, Skovorodin E, Sharipov A, Chudov I (2020). The use of biostimulant for increasing the body weight gain of chickens. Periodico. Tche. Quimica., 17(35): 800-812.

- Gabitov II, Negovora AV, Khasanov ER, Galiullin RR, Farhshatov MN, Khamaletdinov RR, Martynov VM, Gusev D, Yunusbaev NM, Razyapov MM (2019). Risk reduction of thermal damages of units in machinery heat preparation for load acceptance. J. Eng. Appl. Sci., 14(3): 709-716. https://

\section{doi.org/10.36478/jeasci.2019.709.716}

- Guber NB, Morozova NI, Eliseenkova MV, Sereda TI, Tamaev SA (2020). Morphology and quality of beef with regard to a biostimulator used in the diet of animals. IOP Conf. Ser. Earth Environ. Sci., 613(1): 012044. https://doi. org $/ 10.1088 / 1755-1315 / 613 / 1 / 012044$

- Jitesh S, Geetha RV (2017). Anti-Inflammatory activity of Glycrrhizaglabra extract-an in vitro study. J. Pharm. Sci. Res., 9(4): 451-452.

- Khasanov ER, Gabitov II, Mudarisov SG, Khamaletdinov RR, Rakhimov ZS, Akhmetyanov IR, Farkhutdinov IM, Masalimov IH, Musin RZ (2019). Justification of parameters of seed treater with an eccentrically fixed drum influencing the motion character and seed treatment modes. Bulg. J. Agric. Sci., 25(2): 119-128.

- Makarova VN, Koryukina MV, Badeeva OB, Simanova IN (2021). The use of Immunostimulants for the animal diseases prevention. IOP Conf. Ser. Earth Environ. Sci., 677(5): 052103. https://doi.org/10.1088/1755-1315/677/5/052103

- Ming LJ, Yin ACY (2013). Therapeutic effects of glycyrrhizic acid. Nat. Prod. Commun., 8(3): 415-418. https://doi. org/10.1177/1934578X1300800335

- Nasrin M, Siddiqi MNH, Masum MA, Wares MA (2012). Gross and histological studies of digestive tract of broilers during postnatal growth and development. J. Bangladesh Agric. Univ., 10(1): 69-77. https://doi.org/10.3329/jbau. v10i1.12096

• Nishi Y, Tsukano K, Otsuka M, Tsuchiya M, Suzuki K (2019). Relationship between bronchoalveolar lavage fluid and plasma endotoxin activity in calves with bronchopneumonia. J. Vet. Med. Sci., 7(81): 1043-1046. https://doi.org/10.1292/ jvms.18-0643

- Okovity SV, Raikhelson KL, Volnukhin AV, Kudlai DA (2020). Hepatoprotective properties of glycyrrhizic acid. Exp. Clin. Gastroenterol., 184(12): 96-108. https://doi. org/10.31146/1682-8658-ecg-184-12-96-108

- Pushkarev IA, Shanshin NV, Chekunkova JA, Martynov VA, Burtseva SV (2021). Effect of different doses of the tissue biostimulant on some indicators of the immune status of heifers at the age of 6 months. IOP Conf. Ser. Earth Environ. Sci., 677(4): 042036 https://doi.org/10.1088/17551315/677/4/042036

- Skovorodin EN, Bagautdinov AM, Gimranov VV, Ivanov AI, Karimov FA, Kirilov VG, Khokhlov RY, Bazekin GV, Gatiyatullin IR, Dyudbin OV (2018). Morphogenesis of bovine ovaries in prenatal ontogenesis in norm and in pathology of metabolism in cows-mothers. J. Eng. Appl. Sci., 13: 8768-8781.

- Smolentsev SY, Korosteleva VP, Matveeva EL, Nurgalieva AR, Nurgaliev FM (2019). Assessment of influence of biostimulating medicines on the cow milk cheeseability. IOP Conf. Ser.: Earth Environ. Sci. 315(4): 42-44. https:// doi.org/10.1088/1755-1315/315/4/042044

- Sultanova RR, Gabitov II, Yanbaev YA, Yumaguzhin FG, Martynova MV, Chudov IV, Tuktarov VR (2019). Forest melliferous resources as a sustainable development factor of beekeeping. Isr. J. Ecol. Evol., 65(3-4): 77-84. https://doi. org/10.1163/22244662-20191049

- Tolstikova TG, Khvostov MV, Bryzgalov AO (2009). The complexes of drugs with carbohydrate-containing plant metabolites as pharmacologically promising agents. Mini Rev. Med. Chem., 9(11): 1317-1328. https://doi. org/10.2174/138955709789878123 
- Tucker IM, Burley A, Petkova RE, Hosking SL, Penfold J, Thomas RK, Li PX, Webster JRP, Welbourn R, Doutch J (2021). Adsorption and self-assembly properties of the plant based biosurfactant, Glycyrrhizic acid. J. Colloid Interf. Sci., 598: 444-454. https://doi.org/10.1016/j.jcis.2021.03.101
-Wang BK, Mao, Y-L, Gong L, Wang Y-B, Li W-F (2018). Glycyrrhizic acid activates chicken macrophages and enhances their Salmonella-killing capacity in vitro. J. Zhejiang Univ. Sci. B., 19(10): 785-795. https://doi. org/10.1631/jzus.B1700506 